\title{
Interaction of Dense Shelf Waters of the Barents and Kara Seas with the Eddy Structures
}

\author{
G. A. Platovi, 2, *, E. N. Golubeva ${ }^{1,2}$ \\ ${ }^{1}$ Institute of Computational Mathematics and Mathematical Geophysics, Siberian Branch \\ of Russian Academy of Sciences, Novosibirsk, Russian Federation \\ ${ }^{2}$ Novosibirsk National Research State University, Novosibirsk, Russian Federation \\ * platov.g@gmail.com
}

\begin{abstract}
Purpose. Considered are the processes of dense bottom water formation in winter in the region of the Novaya Zemlya northwestern coast, its further propagation (cascading) towards the St. Anna trough and then to the open ocean. The goal of the paper is to show that the process of such propagation is closely related to generation of the mesoscale eddies.

Methods and Results. The data of available measurements indicate only some residual forms of such a movement, since they cover mainly a summer season. Numerical study was carried out using the system of the nested models SibCIOM and SibPOM. In course of the numerical experiments it became possible to show the system capability in describing the water bottom structure and to reproduce the process of bottom water propagation in details. Analysis of the above-mentioned process has revealed energy conversion of the available potential energy of a regular motion into the potential energy of eddy formations. The eddy structures' ageostrophicity, in its turn, contributes to the accelerated advancement of dense shelf waters downard along the sloping bottom.

Conclusions. One of the important features of cascading is that at the initial stage, it is accompanied by active generation of the mesoscale eddy structures. Both processes interact energetically and contribute to increase of heat and mass exchange between the shelf and the open ocean. Proper description of this exchange is a prerequisite for successful modeling of the intermediate and deep water thermodynamics in the Arctic Ocean.
\end{abstract}

Keywords: Arctic Ocean, Kara Sea, formation of water masses, cascading, mesoscale eddy.

Acknowledgements: The work was carried out at support of the Russian Foundation for Basic Research, grant No 17-05-00382, and using resources of the Center for Collective Use "Siberian Supercomputer Center” ICMMG SB RAS.

For citation: Platov, G.A. and Golubeva, E.N., 2019. Interaction of Dense Shelf Waters of the Barents and Kara Seas with the Eddy Structures. Physical Oceanography, [e-journal] 26(6), pp. 484-503. doi:10.22449/1573-160X-2019-6-484-503

DOI: $10.22449 / 1573-160 \mathrm{X}-2019-6-484-503$

(c) 2019, G. A. Platov, E. N. Golubeva

(C) 2019, Physical Oceanography

\section{Introduction}

The process of formation and distribution of dense waters on the shelf of the marginal seas is one of the main in terms of the shelf and the open ocean interaction. In the absence of such relation the deep ocean could be considered within the boundaries of the shelf slope with no regard to shallow areas. However, it is the processes on the shelf, and only those of them as a result of which sufficiently dense waters are formed that can reach the corresponding depths, largely determine the structure of the intermediate and deep waters of the World Ocean. Particularly, the vertical structure of the Arctic Ocean waters in a layer below 500-700 m cannot be explained without the assumption that shelf processes are actively involved in their formation.

The formation of dense waters in the Arctic is often associated with the development of wind polynya, which arises as a result of the wind action when its direction contributes to the ice movement off the coast and the formation of 
a water surface free from ice (see, for example, [1, 2]). Cold eastern winds in the area of Novaya Zemlya western shores often contribute to the formation of polynya here [1]; as a result, more than $10 \mathrm{~m}$ of ice (on average) forms in this polynya during one winter period [3]. Such an active growth of young ice leads to an increase in salinity and, accordingly, in water density, the development of convective motion and the involvement of bottom Atlantic waters of the Barents Sea $[1,4]$. As a result, a bottom layer of dense water is formed with a temperature of about $-0.5{ }^{\circ} \mathrm{C}$ which makes up half of the flux coming from the Barents Sea to the Kara Sea.

Previous studies showed that the interannual variability in the intensity of dense water formation is significant (see, for example, [5]) and potential sources of variability in the characteristics of dense water formation were identified [2, 5-9]. An important characteristic is the salinity of water before freezing, and for the region of Novaya Zemlya western coast the determining factor is the presence of desalinated waters of river origin carried by the Norwegian and Novaya Zemlya coastal currents [2, 5, 6]. However, in [7] it was shown that the processes of ice freezing and melting are more important than river waters and, according to the results of [9], ice import through the northern boundaries of the sea also plays an important role.

Another source of variability in the rate of dense water formation is the vertical stability of the water column [7, 8]. According to [7], the initial stratification depends on the Atlantic waters effect on the rate of ice freezing and melting and in [8] it is argued that the flux of Atlantic waters to the shelf of the Barents Sea can cause negative feedback both for penetrating convection and for ice growth. The latter is important for the formation of dense waters due to salt evolution [1-3]. Moreover, it came to be understood that the climate of the region is largely dependent on Atlantic incomes. In [10] it was shown that the key factor in reconstruction of thermohaline fields on large time scales is the interaction with the Atlantic Ocean - the source of heat and salt water. Any variation in the characteristics of this flux will inevitably affect the production of dense water [7]. High rate of ice melting in summer and the strong influx of Atlantic waters intensify stratification and hamper the formation of bottom dense waters in winter. In [5] the importance of variability of the Atlantic water characteristics, arising as a result of significant mixing and involvement as a result of the distribution of dense bottom waters along the sloping bottom (cascading), formed in shallow areas and moving towards the recesses in the Barents Sea and towards the St. Anna Trough. According to [11], due to the cascading process (or shelf convection) dense water formed as a result of overcooling or ice formation on the continental shelf is involved in the formation of intermediate or deep waters of the open ocean.

The presence of preconditions for the formation of dense waters is also important and can be associated with both local ice melting and the properties of the Novaya Zemlya current [4]. Dense water mainly flows into the Kara Sea where it makes up 63\% (1.2 Sv) of the total inflow from the Barents Sea, and its average density is $1028.07 \mathrm{~kg} / \mathrm{m}^{3}$. The dense water production is maximal in the shallow area when the Barents Sea is in a cold state (small influx from the Atlantic and a lot of ice). During warm time in the presence of strong transit of Atlantic waters most of dense water is formed on the shelf due to the general cooling of Atlantic waters. Nevertheless, in [4], based on their own results, the authors indicate that during 
extremely warm periods (the 1950s and the end of the 2000s) the total production of dense water drops significantly.

Thus, in order to understand the variability of dense water formation it is necessary to study large-scale circulation, hydrography, atmospheric forcing and the dominant mixing mechanisms that make shelf waters more suitable for the formation of dense water.

The main objectives of this work are:

- the study of conditions for the formation of dense bottom waters on the shelf of the Barents and the Kara Seas and their distribution towards the open ocean;

- the analysis of the development of eddy processes accompanying this movement.

In order to carry out the study, we are to use numerical modeling method; therefore, the results of comparing model fields with observational data are also presented in the work.

\section{The study area}

The areas of our interest, for which, according to a number of studies $[2,5,6]$, the formation and distribution of dense bottom waters are characteristic, are shown in Fig. 1. In the area indicated by letter A coastal polynya forms during winter and early spring and the formation of dense waters occurs due to the active freezing of young ice and cooling of the ocean open surface. It is also possible that upwelling makes some contribution as a result of which the bottom layer of Atlantic waters rises to the surface and cools. As it is salty due to the cooling, it acquires the density of deep Arctic waters. In addition, in the 2000s even in winter the floating ice boundary was located near the northern tip of Novaya Zemlya, which also includes the ice formation mechanism at the ice boundary in the polynya formed by the incoming warm waters of Atlantic origin.

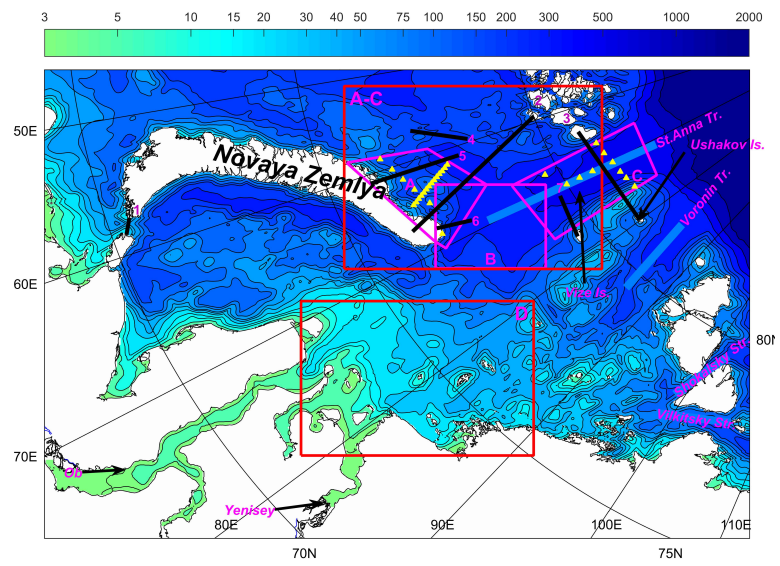

F i g. 1. Topography of the Kara Sea including indications of location of the key geographical objects: $A$ - the area of formation of dense bottom waters, $B$ - the area where these waters reach the headwaters of the St. Anna trough, $C$ - the area oriented along the axis of the St. Anna trough, $A-$ $C$ - the region uniting these areas, $D$ - the region where the river water plume develops. The sections are shown by the black lines including the marks: 1 - the Strait of Kara Gate; 2 - opening between the Franz Josef Land and the Novaya Zemlya, 3 - mouth of the St. Anna trough, 4 - depression in the bottom topography through which the Atlantic waters flow into zones $A, B$ and $C$; 5 and $6-$ coastal sections, 7 - cross section of the right slope of the St. Anna trough. Yellow triangles indicate position of the points where the CTD measurements used in this work were performed 
The second region, indicated in Fig. 1 by letter $B$, is a zone of further distribution of formed dense waters. In fact, this is the headwaters of St. Anna trough adjacent to the northern tip of Novaya Zemlya. Owing to the proximity of the island, it is also possible that polynya appears in the presence of winds of the corresponding direction. However, judging by the available data [12] this does not occur here as often and not as long as in zone $A$.

The third region, marked with the letter $C$, is the zone of the main part of St. Anna trough, the mouth of which opens towards the Amundsen basin, the deepest part of the Arctic Ocean. We expect here the development of active cascading as dense waters move towards the open ocean.

\section{The system of nested models}

Despite the significant progress achieved in the field of the Arctic Ocean numerical modeling [13], the results obtained on the basis of large-scale models can vary significantly. For example, in [14] when comparing the balance of kinetic and available potential energy, it was shown that the energy balance obtained using large-scale models significantly differs below the abyssal level. More recent experiments such as Coordinated Ocean-ice Reference Experiments - Phase II (CORE-II) [15] have contributed to the understanding of significant regular errors in the Arctic Ocean modeling. In particular, it was noted that modern large-scale models need a more accurate description of the influx of Atlantic waters into the Arctic and the formation of dense water fluxes along the Arctic shelf slopes.

For carrying out the study we used a system of nested numerical models of the ocean and its shelf seas developed at ICMMG SB RAS. The model embedding scheme is given earlier in [16]. The main idea is that the Laplace operator, which describes the thermal conductivity and diffusion of the salt, was applied only to deviations of temperature and salinity from their large-scale distributions. Feedback in this case was not taken into account. (For other embedding options see [17] and references therein).

CORE-II reanalysis data, including the necessary set of characteristics of the lower atmosphere, the rate of precipitation and the incoming downward long and short-wave radiation [12] was used as atmospheric forcing.

Analysis of the simulation results was carried out for 2007-2008, since during this period, in accordance with the tasks of the International Polar Year, a significant amount of data was obtained in the field of interest to us.

\section{SibCIOM model}

Siberian Coupled Ice-Ocean Model (SibCIOM) [18, 19], historically associated with the model [20], is used to simulate the large-scale distribution of hydrodynamic fields in the Arctic Ocean and the North Atlantic. The model equations are obtained taking into account the heat, salt and momentum conservation laws using traditional Boussinesq approximations, hydrostatics and rigid-lid approximation using the method of splitting into physical processes [21]. The mode separation method provides the separation of calculations for the barotropic and baroclinic modes. The barotropic mode is described using the equation for the integral stream function and the barotropic velocity components. Advective fluxes are approximated using Quadratic Upstream 
Interpolation for Convective Kinematics with Estimated Streaming Terms (QUICKEST) scheme [22]. The parameterization of the upper mixed layer is carried out taking into account the Richardson number [23]. No-slip and impermeability conditions are realized on solid sections of the boundary. On the liquid sections of the boundary in the Bering Strait and in the mouths of the most significant rivers seasonal discharge variability is preset. On the southern stretch along the line of $20^{\circ} \mathrm{S}$ the transport that compensates for the previous tributaries uniformly along the entire boundary is preset.

The ocean model works in conjunction with CICE 3 ice model [24] which describes the thermodynamics of five categories of ice and one category of snow [25] and uses a semi-Lagrangian approach to describe the advective transport [26].

The model area covers the Atlantic Ocean north of $20^{\circ} \mathrm{S}$ and the Arctic Ocean with a three-pole coordinate system, which has a horizontal resolution of $0.5^{\circ}$ at the equator and at mid-latitudes, and within 10-25 km in the circumpolar region. Vertically the model has 38 fixed unevenly distributed levels with a minimum resolution of $5 \mathrm{~m}$ at surface. The model takes into account the influx of 52 most significant rivers of the region*.

The model of the Kara Sea and the eastern Barents Sea

SibPOM sigma coordinate shelf model, which is a modification of the Princeton University Princeton Ocean Model (POM) [27], was used as such model. It includes the parameterization of vertical turbulent processes and the correction of the horizontal pressure gradient [28]. The simulation area is shown in Fig. 1, the quasi-regular grid of the region is constructed on the basis of a spherical coordinate system with the poles selected so that the new equator is the central axis of the Kara Sea, while the horizontal resolution is $3-4 \mathrm{~km}$, which, according to [29], allows reproducing only large mesoscale eddies .

\section{Numerical modeling results}

Comparison with previous modeling results

The modeling results demonstrate a complex structure of currents in the region of our interest. It should be noted that the main circulation features described in previous works [30,31] are only partially manifested in numerical calculations for 2007-2008. Moreover, as in [32-35], it can be noted that the Kara Sea circulation varies significantly depending on the season and the prevailing atmospheric forcing. The interaction with the open part of the Arctic Ocean is carried out along the St. Anna trough and Voronin trough.

Transports through the main straits of the simulated region, (Sv)

\begin{tabular}{l|c|c}
\hline Location of mouths & SibPOM & SibCIOM \\
\hline Inflow through the Strait of Kara Gate & 0.10 & 0.52 \\
Inflow between the Franz Josef Land and the Novaya & & \\
Zemlya & 0.88 & 1.55 \\
Transport between the Franz Joseph Land and the & & \\
Ushakov Island & 1.07 & 1.56 \\
\hline
\end{tabular}

* Vorosmarty, C.J., Fekete, B.M. and Tucker B.A., 1998. Global River Discharge, 1807-1991, V. 1.1 (RivDIS). Oak Ridge, Tennessee, USA: ORNL DAAC. https://doi.org/10.3334/ORNLDAAC/199 488

PHYSICAL OCEANOGRAPHY VOL. 26 ISS. 6 (2019) 


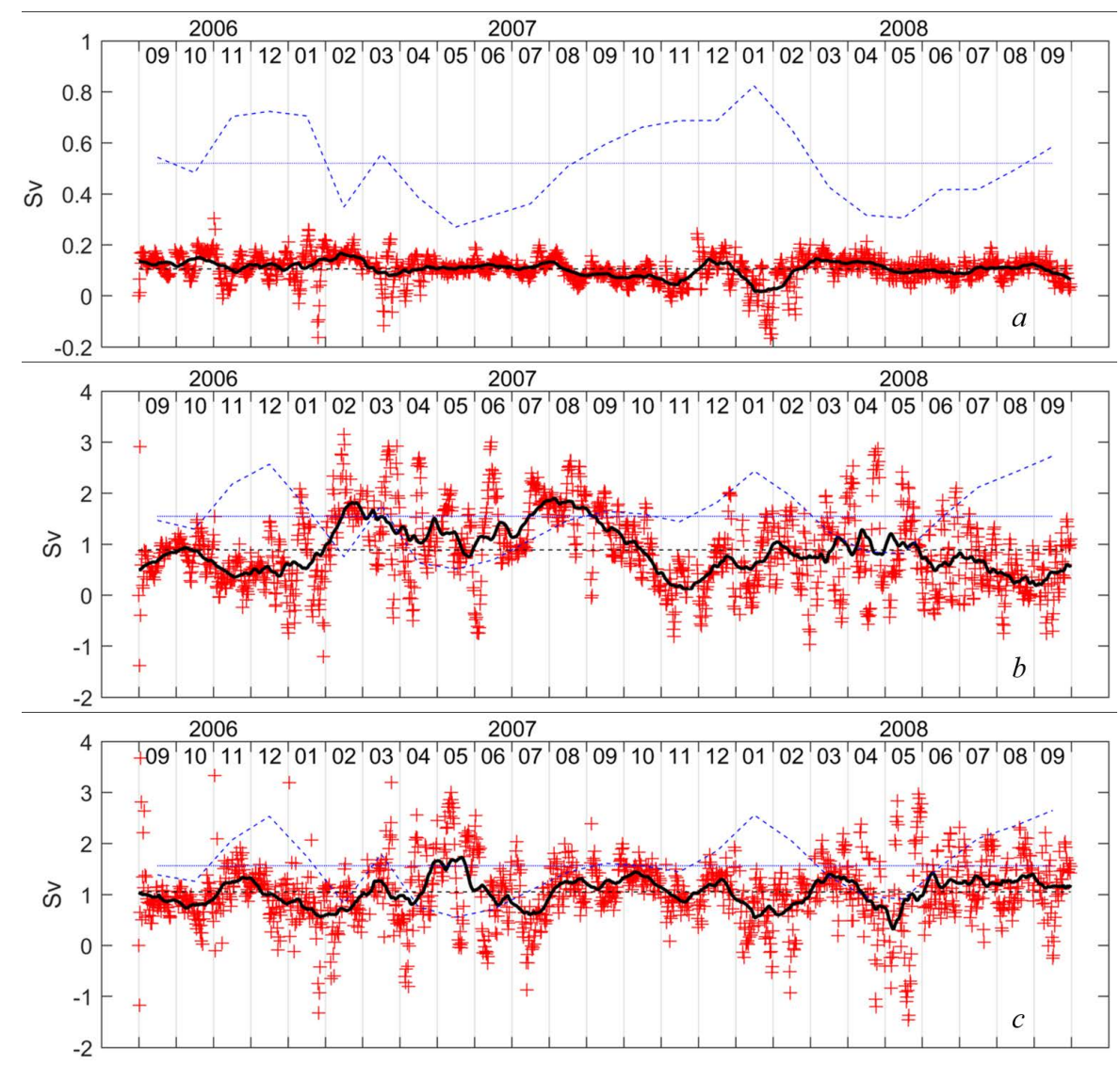

F i g. 2. Time series of water transport (Sv) through sections 1-3 (Fig. 1): $a$ - the Strait of Kara Gate, $b$ - opening between the Franz Josef Land and the Novaya Zemlya, $c$ - strait between the Franz Joseph Land and the Ushakov Island. Red symbols "+” are the values obtained by the SibPOM model, black line is their sliding average, blue dotted line is a result of the large-scale SibCIOM model

The transport of water entering the Kara Sea through the Kara Gate Strait during the modeling period was, on average, $0.1 \mathrm{~Sv}$ (table), varying from -0.1 to $0.3 \mathrm{~Sv}$ (Fig. 2, a). According to one of the earliest assessments [36], the transport is slightly higher -about $0.7 \mathrm{~Sv}$. According to the results of large-scale modeling in 1998 [37], it ranged from -0.023 to 0.015 Sv. Later estimates [38, 39] show the values of about $0.6 \mathrm{~Sv}$. In our case, the large-scale model gives an average value of $0.52 \mathrm{~Sv}$ (table, Fig. 2) with a variation range of $0.3-0.8 \mathrm{~Sv}$. The maximum falls on December - January, the minimum - on May - June. Also, according to assessments [39] approximately 1.2 Sv enters the Kara Sea from the Barents Sea between Novaya Zemlya and Franz Joseph Land. According to the results of regional SibPOM model in 2007-2008 this transport was $0.88 \mathrm{~Sv}$, while calculations using the large-scale SibCIOM model yield almost 2 times more, 1.55 Sv (table, Fig. 2, b). According to assessments [39], most of this inflow is transported through the of St. Anna and Voronin troughs, as well as through the straits of Severnaya Zemlya. According to the results of our calculations the removal of water through the St. Anna trough is $1.07 \mathrm{~Sv}$ according to the regional model and $1.56 \mathrm{~Sv}$ according to SibCIOM model (table, Fig. 2, c). 
From the total balance it follows that, according to the regional model, the inflow through the straits under consideration is not enough to compensate for the water removal through St. Anna trough, and, therefore, additional inflows are made through other sections: Franz Josef, Vilkitsky and Shokalsky Straits. According to the results of the large-scale model, these inflows, on the contrary, exceeded the transport through the St. Anna trough and, consequently, increased the transport through the Voronin trough and the Severnaya Zemlya straits.

\section{Comparison of modeling results with the measurement data}

The data obtained within the framework of the International Polar Year (publicly available) using CTD profilers (conductivity, temperature, depth) are considered to be the most reliable in the Arctic. However, the possibilities of such measurements are limited due to the presence of ice cover, and therefore the measurements cover mainly such periods of time and areas where nonnavigable ice is absent. In terms of studying the formation and distribution of dense waters, this is a significant limitation. In fact, we can use the available measurement data to monitor either the development of preconditions for the formation of water or the residual anomalies that persist until the beginning of summer in the bottom depressions and canyons.

In May 2007, three temperature profiles were recorded in region $A$, and it can be stated that the difference between the temperature profiles and model calculations at the corresponding depths is within $0.5{ }^{\circ} \mathrm{C}$ and the model gives a slightly overestimated value.

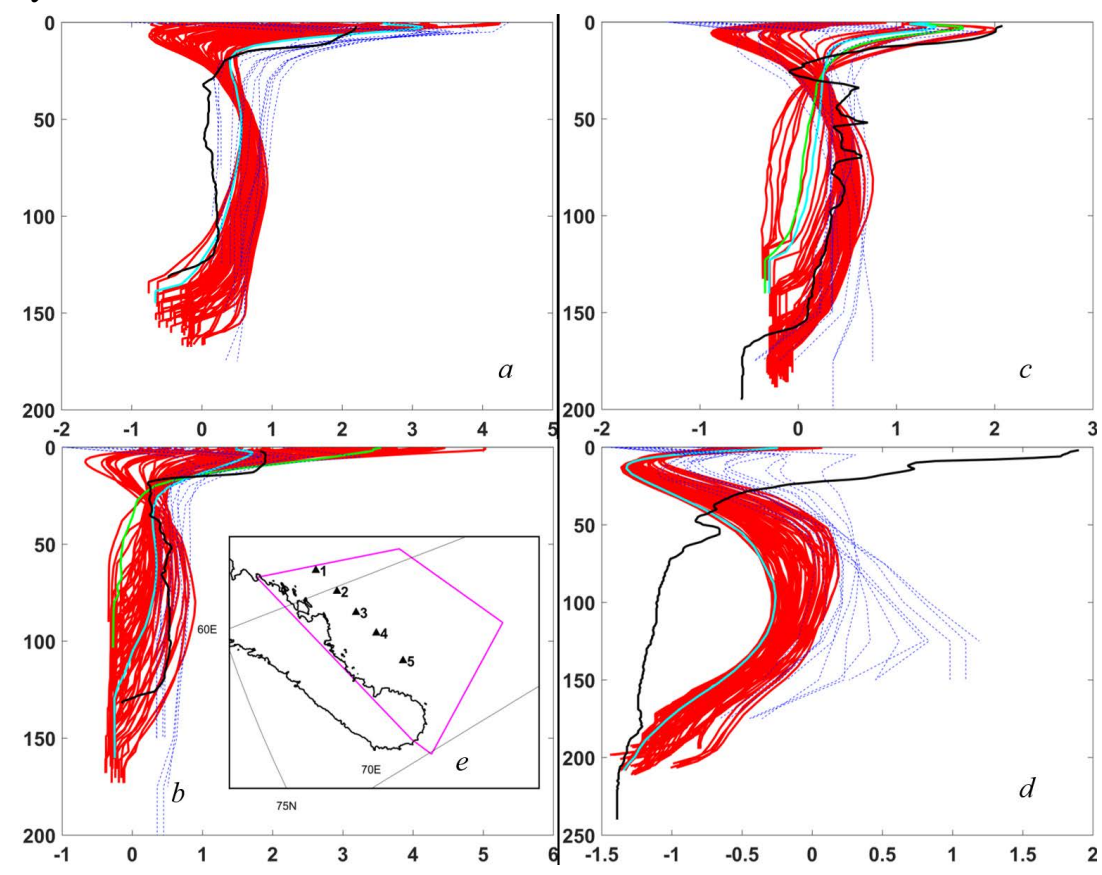

F i g. 3. Comparison of the temperature vertical profiles $(a-d)$ at points $1-4$ obtained on June 21 , 2007; their position is shown in panel (e). Solid black line is the CTD profiler data, blue dashed lines are the large-scale model profiles at the points within the $30 \mathrm{~km}$ neighborhood, red lines are the regional model profiles within the $10 \mathrm{~km}$ neighborhood, green line is one of these profiles with the highest correlation coefficient, cyan line - with the lowest RMS deviation 
5 measurements were carried out in June, four of which were near the lowest point of a small trench located along the Novaya Zemlya shore with depths of 150-200 m. The fifth measurement is in a shallow area with a depth of $100 \mathrm{~m}$. Temperature profiles according to the simulation results and measurement data are in qualitative agreement and demonstrate an approximately homogeneous layer in the range of $30-120 \mathrm{~m}$ with a temperature of about $0.5{ }^{\circ} \mathrm{C}$, above which lies a warmer surface layer, below is a bottom layer of colder water 10-20 m thick with a temperature of -1 to $0{ }^{\circ} \mathrm{C}$. The difference in temperature on the three profiles does not exceed $0.5^{\circ} \mathrm{C}$ and the deviations are approximately symmetrical both in the positive and negative directions (Fig. 3). The homogeneous layer on the fourth profile turned out to be warmer by about $1{ }^{\circ} \mathrm{C}$ according to the modeling results.

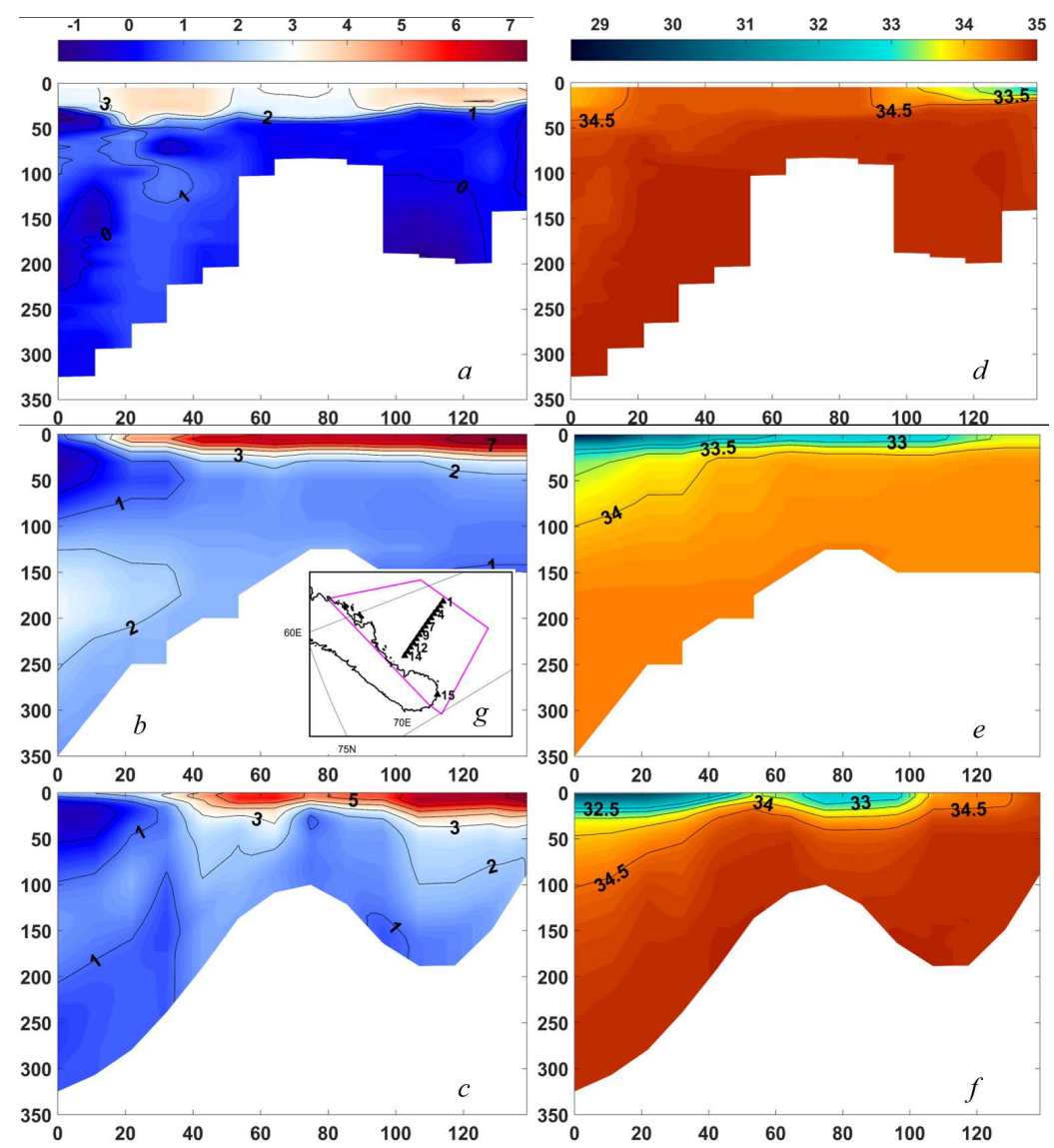

F i g. 4. Vertical cross-section of temperature $\left({ }^{\circ} \mathrm{C}\right)(a-c)$ and salinity $(\%)(d-f)$ constructed by points 1-14 the position of which is represented in panel $(g): a, d$ - based on the data of CTDprofilographs for September, 2007; $b, e$-based on the results of the large-scale model; $c, f$-based on the results of the regional model. The horizontal coordinate is the distance along the section $(\mathrm{km})$, the vertical one is the depth (m)

In September 200715 measurements were performed in zone $A$, 14 of which form a cross section perpendicular to the coastline. In Fig. 4 the temperature and salinity cross section reconstructed from these points (Fig. 4, a, d) as compared with the section obtained from the results of numerical modeling (Fig. 4, $c, f$ ) are 
represented. It can be seen from the comparison that, despite the fact that the largescale model (Fig. $4 b, e$ ) used as the background temperature and salinity distributions have only approximate similarities with the real distribution, the regional model nevertheless reconstructs the main features of the region's hydrology, in particular bottom layer of cold and salt water. However, the temperature of this layer is about $1{ }^{\circ} \mathrm{C}$ higher than the real one, and salinity is about $0.4 \%$ lower. In addition, there is a noticable difference in the upper layer caused by the difference in the position of the fields of the ice-snow cover and the places of its melting. Considering the fact that the large-scale model was integrated under effect of atmospheric forcing taken from the reanalysis data and without using the data assimilation procedure which, according to [40], gives a significant improvement, this difference can be considered quite satisfactory.

Unfortunately, the period of the bottom layer formation is not covered by the available $C T D$ measurements.

In addition, to compare the simulation results with the measurement data the sections in $B$ and $C$ regions were constructed. In zone $B$ residual traces of nearbottom dense waters are barely traceable from the measurement data and model results which suggest that this zone is a transit one and bottom waters are not accumulated here, as well as in summer they are practically absent.

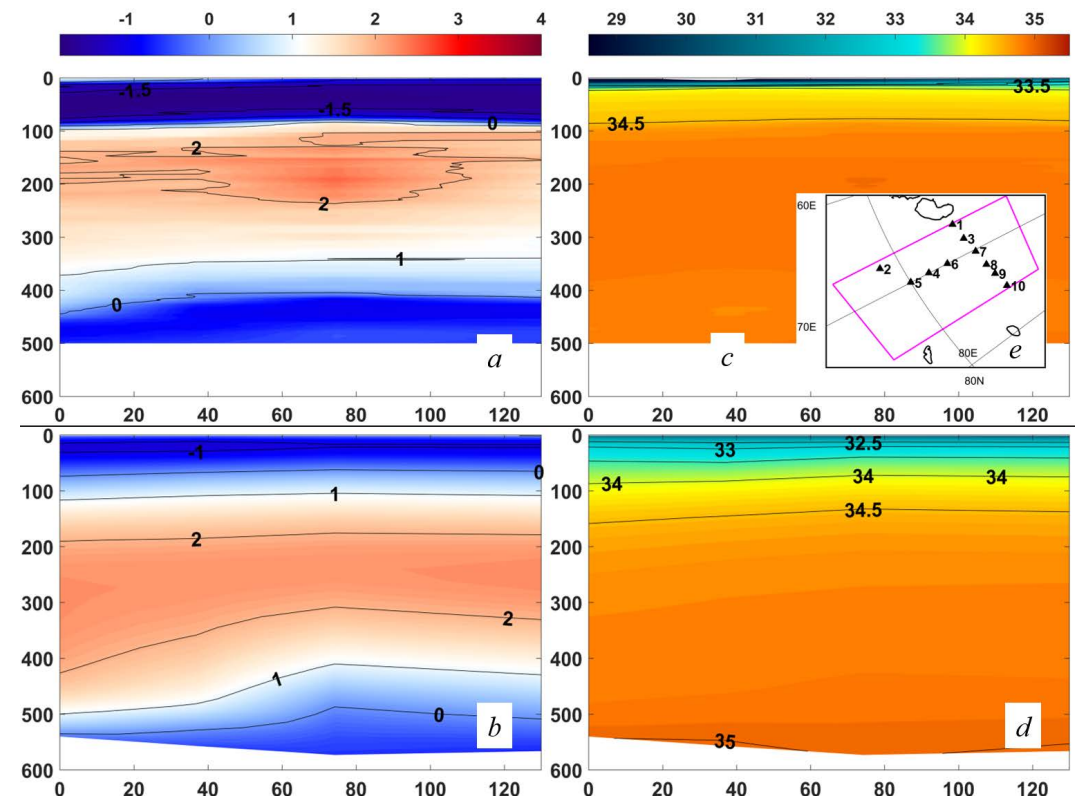

F i g. 5. Vertical sections of temperature $\left({ }^{\circ} \mathrm{C}\right)(a, b)$ and salinity $(\%)(c, d)$ plotted from the measurements at points 4-7 the position of which is represented on panel $(e): a, c-$ based on the CTD data collected in August, 2007; $b, d$ - based on the regional model results. The horizontal coordinate is the distance along the section $(\mathrm{km})$, the vertical one is the depth $(\mathrm{m})$

In zone $C$ the section obtained in August 2007 (Fig. 5) corresponds to the propagation trajectory of the Fram Strait branch of the Atlantic waters, which followed along the shelf slope and turned deep into St. Anna trough along its left slope. Atlantic water enters the trough in a depth range of $50-500 \mathrm{~m}$ and has 
a temperature of about $2{ }^{\circ} \mathrm{C}$. At $450-600 \mathrm{~m}$ depth a cold layer formed in the Barents Sea with temperatures below $0{ }^{\circ} \mathrm{C}$ and salinity of about $35 \%$ is observed.

Analysis of cascading and eddy activity of the region

Making sure that the qualitative picture of the distribution of hydrological characteristics obtained by the regional SibPOM model corresponds to the real distribution, we turn to the main task of the study - the analysis of eddy activity and the cascading process.

We consider the field of the vertical component of $\hat{\zeta}$ relative vorticity [41] (hereinafter referred to as the relative vorticity):

$$
\hat{\zeta}=\left(\frac{\partial v}{\partial \eta}-\frac{\partial u}{\partial \xi}\right) / f,
$$

where $u \quad v$ are the horizontal components of velocity along the curvilinear coordinates of $\xi$ and $\eta$ model; $f$ is Coriolis parameter. In Fig. 6 the distribution of the relative vorticity averaged in the Atlantic water layer $100-250 \mathrm{~m}$ in the region covering $A, B$ and $C$ zones in March 2007 and 2008 is represented. The same figure shows the horizontal velocity field averaged in the same layer. It can be seen that in winter in this region a significant amount of eddies is formed on a scale of $10-50 \mathrm{~km}$ (compared to September of the same years (not shown)). As usual (for the Northern Hemisphere), the most intense eddies of positive vorticity are mainly located on the left from the main stream of Atlantic waters and the ones of negative vorticity - on the right. The region of the relative vorticity greatest variation is located near the Northern Cape of Novaya Zemlya and to the west of it along the stream of Atlantic waters. On the right, in the area of negative vorticity, there is a coastal shallow where (with appropriate winds) wind polynya can form, as well as the dense water anomalies.

In Fig. 7 four sections perpendicular to the trajectories of the Atlantic waters in this region (see sections 4-7 in Fig. 1) are represented. They are constructed according to the calculation results for March 15, 2007, during the period when, based upon Fig. 6, $a$, high eddy activity was noted. The color indicates the velocity component normal to the section with red tones corresponding to the direction of the main stream velocity, blue tones to the opposite current. On section 4 (Fig. 7, a) it can be seen that the movement is almost uniform along the vertical and is tied to a topographic slope with a difference of about $100 \mathrm{~m}$ (from 150 to $250 \mathrm{~m}$ ), a velocity in the core of $20-30 \mathrm{~cm} / \mathrm{s}$ and about $40 \mathrm{~km}$ stream width. Isolines of potential density show that water has a higher density than the environment with a maximum value near the bottom of about $28.0 \mathrm{~kg} / \mathrm{m}^{3}$ (i.e. $1028.0 \mathrm{~kg} / \mathrm{m}^{3}$ ).

On the next section (Fig. 7, $b$, see section 5 in Fig. 1) it can be seen that the current has somewhat weakened (mainly due to the formation of the coastal branch), is still tied to the topographic slope at the same depths. The maximum velocities up to $22 \mathrm{~cm} / \mathrm{s}$ are localized near the bottom. According to the position of the potential density isolines, it is possible to assume the wind polynya occurrence near the coastline along with the formation of heavy water with a density of $28.6 \mathrm{~kg} / \mathrm{m}^{3}$ in it, which ageostrophically spreads down the slope forming features 
characteristic of cascading. The cascading layer boundary, according to the definition [42], approximately coincides with $28.0 \mathrm{~kg} / \mathrm{m}^{3}$ isoline. Following $[42,43]$ we determined position of five points $A, B, C, D, E$, characterizing the cascading state, as follows:

- $A$ - the position of the point is determined by the density maximum on the top of the slope, $\rho_{\max }$;

- $B$-in the case of cascading, following from point $A$ down the slope the density decreases and then increases again when certain depths are reached: point $B$ is a one at which the bottom density reaches a value equal to $\rho_{\max }$ again;

$-C-$ this point is located in the density minimum point $\rho_{\min }$ if we follow along the bottom from point $A$ to point $B$;

$-D$ - this point, unlike the previous ones, is not located at the bottom, but inside the water layer at a depth of point $A$. In [42] it is described as the first point not involved in cascading if we move horizontally from point $A$ in the direction of increasing depth. So, it is a point with the characteristic properties of water corresponding to the cascading environment. Such a formulation does not provide the determination of the unique position of the point, so we decided to take for it the position of the minimum density in horizontal movement from point $A$ to the direction of increasing depth;

$-E$ - this point is located above point $B$ despite the fact that the density in it is equal to the density in the point $C$, i.e. $\rho_{\min }$.

Parameter $h$ is defined as the ratio of the layer thickness above point $A$ (in which the density value is greater than $\rho_{\min }$ ) to the depth of the ocean at point $A$. This dimensionless thickness of the cascading layer varying from 1 (density at point $A$ is greater than $\rho_{\min }$ at all depths) to 0 (i.e. if $\rho_{\max }=\rho_{\min }$ ) is defined in [42] as an indicator of the effectiveness of atmospheric impact on the formation of dense waters. So, $h$ is a proportion of the thickness of dense waters in the total thickness of the basin at point $A$ and the closer these waters are to the surface, the greater is a role of atmospheric forcing in their formation. From the analysis of section 5 it follows that $h$ value is 1 . This indicates that the formation of dense waters has not yet ended and, most likely, continues near the coast. Among the 7 sections considered in [42], obtained in the region of the Novaya Zemlya western coast *, only in one case the atmospheric effect was equally strong, and $h$ parameter is equal to 1 .

Another important characteristic of developing cascading is the parameter equal to the ratio of the density difference inside the cascading layer (maximum minus minimum) to the difference in maximum density inside the same layer with the density of surrounding waters:

$$
r=\frac{\rho_{\max }-\rho_{\min }}{\rho_{\max }-\rho_{D}} .
$$

* Matishov, G., 1998. Climatic Atlas of the Barents Sea 1998: Temperature, Salinity, Oxygen, NOAA Atlas NESDIS vol. 36. Washington, DC: US Government Printing Office. 


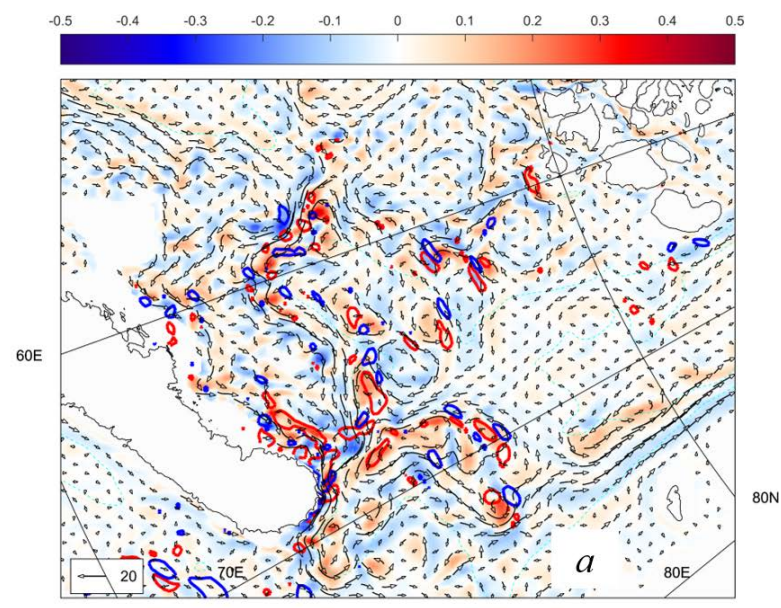

$75 \mathrm{~N}$

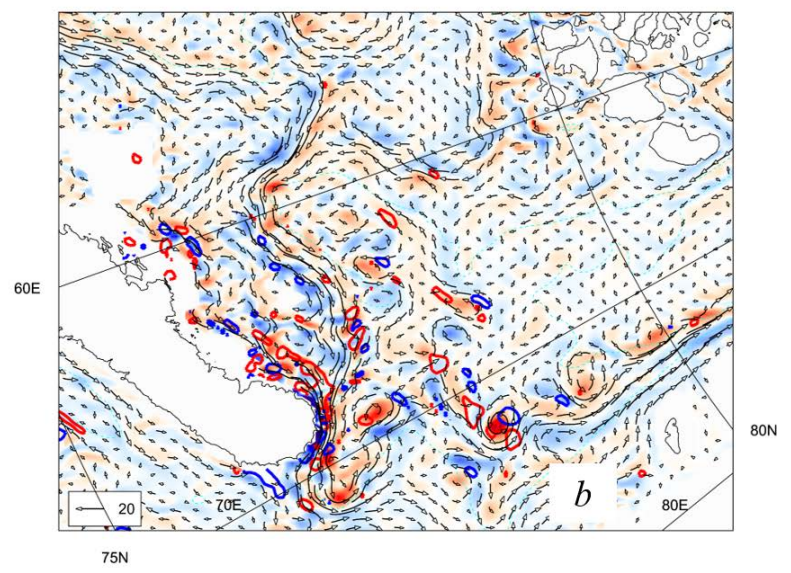

F i g. 6. Relative vorticity fields in the area $A-C$ in March, 2007 (a) and 2008 (b) vertically averaged in the 100-250 m layer. Red shadings correspond to cyclonic vorticity, blue shadings to negative one; arrows indicate the current velocity averaged within the same depth range. Red and blue contours encircle the areas of positive and negative potential energy transformation $B C$. Sample arrows in the lower-left corner of both panels correspond to the velocity of $20 \mathrm{~cm} / \mathrm{s}$

During the lifetime of the cascading process this value changes from a value close to unity at the initiation of the process when the minimum density in the cascading layer and the density of the surrounding waters coincide, to zero at its attenuation when the density difference in the cascading layer is barely identified, i.e. $\rho_{\max } \approx \rho_{\min }$. From the density analysis in Fig. 7, $b$ it follows that in our case this value is 0.63 , i.e. the cascading is in the initial stage of development. The velocity scale of the dense water ageostrophic movement down the slope is determined by the formula from [44]:

$$
V_{N}=g \frac{\delta \rho}{\rho} \frac{s}{f}
$$

where $g \frac{\delta \rho}{\rho}$ is a reduced gravity; $s$ is a modulus of the bottom gradient (see below). 
The assessment shows that, according to the characteristics of section 5 , this velocity is $6.6 \mathrm{~cm} / \mathrm{s}$. Considering that the velocity along the isobaths is $22 \mathrm{~cm} / \mathrm{s}$, it can be concluded that the ageostrophic component of the velocity is approximately $30 \%$ and the velocity vector is directed at an angle of about $17^{\circ}$ to the isobath lines.
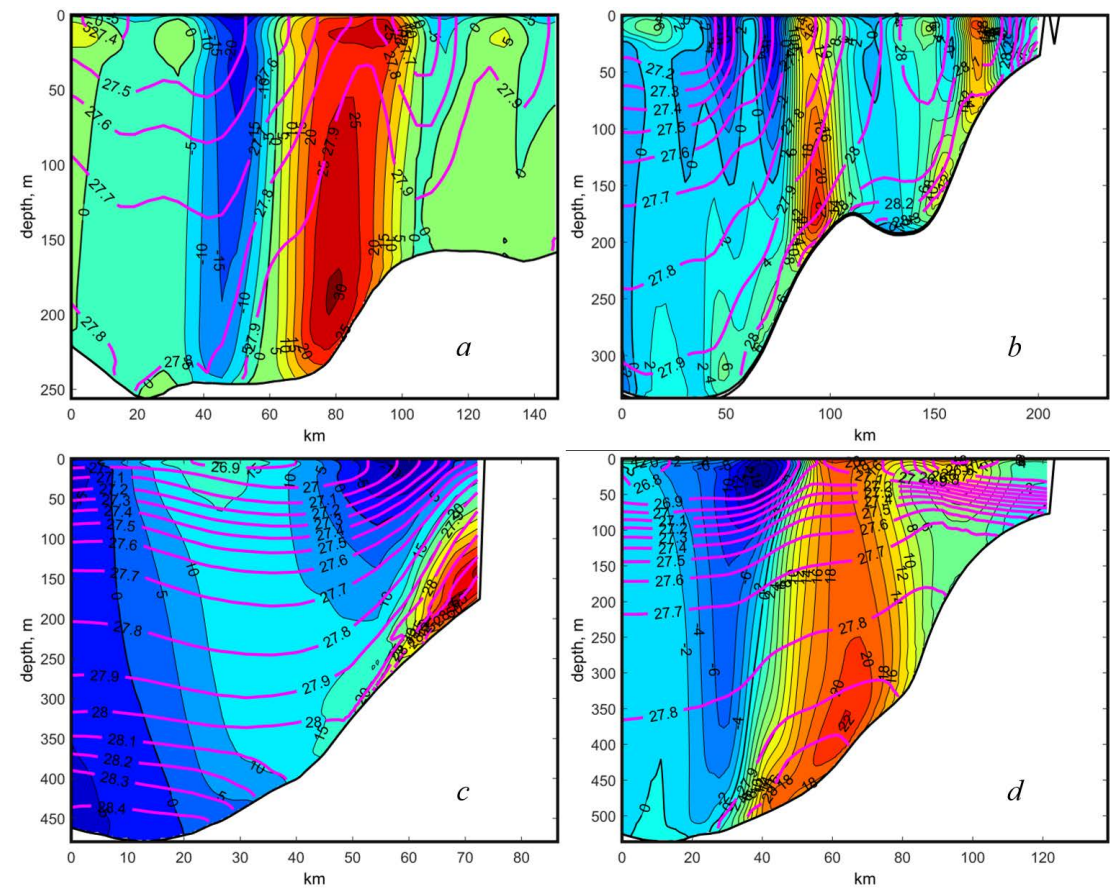

F i g. 7. Vertical cross-sections of current velocity $(\mathrm{cm} / \mathrm{s})$ and potential density $\left(\mathrm{kg} / \mathrm{m}^{3}-1000\right)$. The velocity is represented by the component value normal to the section plane (positive values correspond to the forward direction) and is highlighted by the contours with spot colors. Potential density is represented by the magenta isolines. The directions of sections $(a-d)$ correspond to sections $4-7$ on Fig. 1 . The horizontal coordinate is the distance along the section (km), the vertical one is the depth $(\mathrm{m})$

The third section along the flux, shown in Fig. 7, $c$ (see section 6 in Fig. 1), shows the concentration of the jet core near the bottom in 100-200 m layer and near a sharp slope at the coastline (jump from 0 to $180 \mathrm{~m}$ ), so that the flux width decreases to $10 \mathrm{~km}$. As a result, the velocity increased to $55 \mathrm{~cm} / \mathrm{s}$ in the center of the stream. The behavior of potential density isolines also demonstrates the features characteristic of cascading. However, the formation of dense water under effect of atmospheric conditions is weakened here $(h=0,39)$ and the cascading process, although it is in the middle of its development, is nevertheless closer to the attenuation $(r=0.5)$. The cascading velocity is still high $V_{N}=6.1 \mathrm{~cm} / \mathrm{s}$, however, since the velocity of the main stream increased, the share of ageostrophicity decreased to $11 \%$ and the angle between the velocity vector and the isobath line decreased to $6^{\circ}$.

The fourth section shown in Fig. 7, $d$ (see section 7 in Fig. 1) represents the vertical distribution of water propagation velocity along the axis of the St. Anna trough towards the open ocean. The stream core is concentrated at the bottom at $300-500 \mathrm{~m}$ depth, the maximum velocity is $22 \mathrm{~cm} / \mathrm{s}$, the flux width is up to $50 \mathrm{~km}$. 
The cascading process characteristics indicate that it is practically not related to atmospheric processes $(h=0,24)$, it is in the final phase of its existence ( $r=0.1$ ), its velocity is $V_{N}=1.8 \mathrm{~cm} / \mathrm{s}$, the rotation of the velocity vector is $4.7^{\circ}$ relative to the direction isobath lines. However, even with such a weak advance down the slope it accounts for approximately $0.2 \mathrm{~Sv}$ per $100 \mathrm{~km}$.

An analysis of the same cross sections obtained in September, when the eddy activity is minimal, does not reveal the distribution features characteristic of cascading. From this we conclude that the development of cascading stimulates the development of eddy activity. The mechanism of this stimulation is associated with the transition of the released average available potential energy into the potential energy of the eddy motion. The conversion rate is associated with baroclinic instability and can be calculated according to the simulation results using the formula from [44]:

$$
B C=-\frac{g^{2}}{\overline{N^{2} \rho_{0}}}\left(\overline{u^{\prime} \rho^{\prime}} \frac{\partial \bar{\rho}}{\partial \xi}+\overline{v^{\prime} \rho^{\prime}} \frac{\partial \bar{\rho}}{\partial \eta}\right),
$$

where $\overline{N^{2}}$ is Brunt-Väisälä frequency for average density $\bar{\rho}$, and $\rho^{\prime}, u^{\prime}, v^{\prime}$ values are the mesoscale pulsations of density and horizontal velocity components. In order to calculate this velocity, during the modeling the average values of not only the velocity and density $\bar{u}, \bar{v}, \bar{\rho}$ but also of their covariances $\overline{u \rho}$ and $\overline{v \rho}$ were recorded so that after the model run it would be possible to calculate $\overline{u^{\prime} \rho^{\prime}}=\overline{u \rho}-\bar{u} \bar{\rho}$ and $\overline{v^{\prime} \rho^{\prime}}=\overline{v \rho}-\bar{v} \bar{\rho}$.

In Fig. 6, in addition to the relative vorticity and velocity field, the contours of $B C$ value integrated in the upper 250 m layer are also represented. In this case, red contours encircle the zones of positive energy conversion with an intensity of more than $10^{-3} \mathrm{~W} / \mathrm{m}^{2}$ (i.e. the transition of the average potential energy to potential energy of eddy motions), and blue contours - the zones of the reverse transition. It is noteworthy that the previously noted eddy activity during the period of possible cascading also coincides with active transitions in the energy spectrum.

It should also be noted that the localization of extreme regions of the relative vorticity and $B C$ conversion rate coincide. This can be explained by the fact that the active eddy movement in the areas of the inclined bottom leads to an increase in the ageostrophic component of the movement, i.e. the movement across the isobath lines. In its turn, this enhances the cascading process (if necessary prerequisites are present) namely, the formed anomaly of dense water in the area of the coastal shallow. The presence of dense water at the top of the slope is a source of available potential energy, which, in turn, feeds the eddy processes on the slope.

In order to assess how interconnected the eddy processes are with cascading, we consider the integral value of the relative vorticity $R V$ and the mass flux $M F$, associated with cascading, as quantities characterizing these processes. The first is the integral of the relative vorticity:

$$
R V=\int_{\Omega-z_{2}}^{-z_{1}} \int_{\zeta} d z d \Omega
$$


where $z_{1}, z_{2}$ is a depth range covering the most active movement; $\Omega$ is a region of eddy activity. As $\Omega$ we take zone $A$ and a depth range, according to Fig. 7, $100-250 \mathrm{~m}$. Since the integral (according to the Stokes theorem) is equal to the velocity circulation along the region's contour and does not give a complete picture of the eddy field structure inside the region, it is convenient to represent it in the form of two terms:

$$
R V=R V^{+}-R V^{-}=\iint_{\Omega_{+}} \int_{-z_{2}}^{-z_{1}} \hat{\zeta} d z d \Omega-\int_{\Omega_{-}} \int_{-z_{2}}^{-z_{1}}|\hat{\zeta}| d z d \Omega,
$$

where $\Omega_{+}$and $\Omega_{-}$are two subregions $\Omega$, so that $\Omega=\Omega_{+} \cup \Omega_{-}$, at the same time $\Omega_{+}$represents a set of points in which $\hat{\zeta}>0$, and $\Omega_{-}$is a set of points in which $\hat{\zeta}<0$.

As the cascading process is related to the motion along the inclined bottom, gradient $\vec{s}$ of ocean depth $H$ is the main parameter:

$$
\begin{gathered}
\vec{s}=\vec{\nabla} H=\left(\frac{\partial H}{\partial \xi}, \frac{\partial H}{\partial \eta}\right), \quad s=\sqrt{\left(\frac{\partial H}{\partial \xi}\right)^{2}+\left(\frac{\partial H}{\partial \eta}\right)^{2}}, \\
\vec{n}=\left(n_{\xi}, n_{\eta}\right)=\left(\frac{\partial H}{\partial \xi}, \frac{\partial H}{\partial \eta}\right) / s, \\
\vec{l}=\left(n_{\eta},-n_{\xi}\right),
\end{gathered}
$$

where $\vec{n}$ is a unit vector perpendicular to the isobath lines and directed towards the increasing depth of the ocean; $\vec{l}$ is a unit vector perpendicular and directed along the isobaths so that the deeper regions remain on the left.

We consider the projection of the velocity vector on the perpendicular and tangent directions with regard to the isobath lines:

$$
\begin{aligned}
& u_{n}=(\vec{u} \cdot \vec{n})=u n_{\xi}+v n_{\eta}, \\
& u_{l}=(\vec{u} \cdot \vec{l})=u n_{\eta}-v n_{\xi} .
\end{aligned}
$$

Accordingly, the elementary increments along $\vec{n}$ and $\vec{l}$ are equal to

$$
\begin{aligned}
& d s_{n}=\sqrt{\left(d \xi n_{\xi}\right)^{2}+\left(d \eta n_{\eta}\right)^{2}}, \\
& d s_{l}=\sqrt{\left(d \xi n_{\eta}\right)^{2}+\left(d \eta n_{\xi}\right)^{2}} .
\end{aligned}
$$


Using these notations, $d M F$ mass flow causing by cascading can be represented in each model box as

$$
d M F=\int_{-H}^{-h_{c}} u_{n} d s_{l} d z .
$$

When determining the boundaries of vertical integration, the criterion [43] is used:

$$
\left\{\begin{array}{c}
u_{n}>0 \\
\frac{(\vec{\nabla} \rho \cdot \vec{s})}{\rho}>\varepsilon
\end{array},\right.
$$

where, in contrast to the mentioned work, the quantity $\varepsilon$ was taken equal to 0 instead of $2 \cdot 10^{-8}$. Summing up all the boxes from $\Omega$, we obtain the total value of $M F$ in this region.

The time series of $R V^{+}, R V^{-}$and $M F$ obtained in such a way, are given in Fig. 8. It can be seen that the greatest eddy activity in zone $A$ occurs in March, and the positive eddies are 1.5-2 times more intense. Such activation occurs precisely at the end of winter (when the area covered with ice is maximal) and it cannot be caused by direct atmospheric exposure. There is also no reason, due to the seasonal nature, to intensify the main stream of Atlantic waters and increase its barotropic instability as a mechanism for the formation of mesoscale eddies. Therefore, the formation of dense waters in the area of wind polynya near the shores of the Novaya Zemlya northern part is the most likely source of eddy energy. It is in March that the cascading process begins in the coastal region. The velocities of regular movement and volumes of dense masses at the initial stage are still small. Therefore, the main mechanism of propagation is eddy activity. In subsequent periods, the development leads to the formation of regular movements and eddy activity decreases.

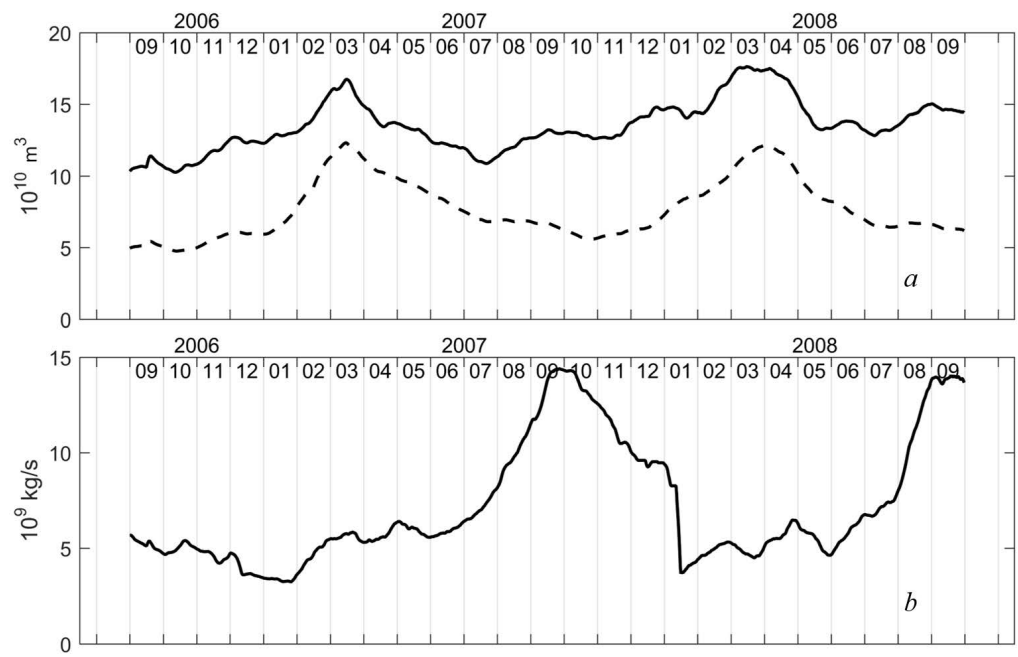

F i g. 8. Temporal variability of the motion integral characteristics in zone $A$ : $a$ - solid line denotes the integral of positive values of relative vorticity, $R V^{+}$, dashed line - the integral of negative values of relative vorticity, $R V^{-} ; b$ - mass flow rate of water $(\mathrm{kg} / \mathrm{s})$ involved in cascading, $M F$ 
The resulting picture suggests that the processes of eddy formation in this region and cascading are closely related to each other. The formation of dense water as a result of young ice freezing in the polynya area and its ageostrophic movement towards the relief inclination leads to the formation of mesoscale eddies fueled by the released potential energy. On the other hand, mesoscale eddies developing in an area with inclined bottom inevitably enhance the water exchange in the direction perpendicular to the isobath line, which, in its turn, leads to the further cascading development. However, cascading reaches its maximum intensity in late summer when the formed anomalies of dense water are picked up by regular currents. Possible processes that also contribute to the development of cascading at this stage are submesoscale eddies (the maximum activity of which occurs in July [45]), eddy motions localized in the jet region and also transport in the near-bottom Ekman layer.

\section{Conclusions}

Using the mathematical modeling method we studied the processes of dense bottom water formation in winter near the Novaya Zemlya northwestern coast and its distribution into the open ocean. Using the system of SibCIOM and SibPOM nested models the cascading process is reconstructed in detail. It is shown that at the initial stage cascading is accompanied by an active process of eddy formation. Both processes interact energetically and contribute to an increase in heat and mass transfer between the shelf and the open ocean. Previously obtained conclusion that the adequate reproduction of intermediate and deep water formation of the Arctic Ocean is determined by the correct description of these exchanges is confirmed.

\section{REFERENCES}

1. Martin, S. and Cavalieri, D.J., 1989. Contributions of the Siberian Shelf Polynyas to the Arctic Ocean Intermediate and Deep Water. Journal of Geophysical Research: Oceans, [e-journal] 94(C9), pp. 12725-12738. doi:10.1029/JC094iC09p12725

2. Schauer, U., 1995. The Release of Brine-Enriched Shelf Water from Storfjord into the Norwegian Sea. Journal of Geophysical Research: Oceans, [e-journal] 100(C8), pp.16015-16028. doi:10.1029/95JC01184

3. Winsor, P. and Björk, G., 2000. Polynya Activity in the Arctic Ocean from 1958 to 1997. Journal of Geophysical Research: Oceans, [e-journal] 105(C4), pp. 8789-8803. doi:10.1029/1999JC900305

4. Årthun, M., Ingvaldsen, R.B., Smedsrud, L.H. and Schrum, C., 2011. Dense Water Formation and Circulation in the Barents Sea. Deep Sea Research Part I: Oceanographic Research Papers, [e-journal] 58(8), pp. 801-817. doi:10.1016/j.dsr.2011.06.001

5. Schauer, U., Loeng, H., Rudels, B., Ozhigin, V. K. and Dieck, W., 2002. Atlantic Water Flow through the Barents and Kara Seas. Deep Sea Research Part I: Oceanographic Research Papers, [e-journal] 49(12), pp. 2281-2298. doi:10.1016/S0967-0637(02)00125-5

6. Rudels, B., 1987. On the Mass Balance of the Polar Ocean, with Special Emphasis on the Fram Strait. Norsk Polarinstitutt Skrifter 188. Oslo: Norsk Polarinstitutt, pp. 1-53. Available at: https://brage.npolar.no/npolar-xmlui/bitstream/handle/11250/173528/

Skrifter188.pdf?sequence=1\&isAllowed=y [Accessed: 10 December 2019].

7. Harms, I.H., 1997. Water Mass Transformation in the Barents Sea - Application of the Hamburg Shelf Ocean Model (HamSOM). ICES Journal of Marine Science, [e-journal] 54(3), pp. 351-365. doi:10.1006/jmsc.1997.0226 
8. Backhaus, J.O., Fohrmann, H., Kämpf, J. and Rubino, A., 1997. Formation and Export of Water Masses Produced in Arctic Shelf Polynyas - Process Studies of Oceanic Convection. ICES Journal of Marine Science, [e-journal] 54(3), pp. 366-382. doi:10.1006/jmsc.1997.0230

9. Ellingsen, I., Slagstad, D. and Sundfjord, A., 2009. Modification of Water Masses in the Barents Sea and Its Coupling to Ice Dynamics: a Model Study. Ocean Dynamics, [ejournal] 59(6), pp. 1095-1108. doi:10.1007/s10236-009-0230-5

10. Iakovlev, N.G., 2012. On the Simulation of Temperature and Salinity Fields in the Arctic Ocean. Izvestiya, Atmospheric and Oceanic Physics, [e-journal] 48(1), pp. 86-101. doi:10.1134/S0001433812010136

11. Luneva, M., Myers, P., Ivanov, V., Aksenov, Y., Dukhovskoy, D., Golubeva, E., Platov, G., Wang, Q. and Zhang, W., 2019. Evaluation of Dense Water Cascading and Cross-Shelf Exchange in the Arctic Ocean: Inter-Comparison Project. Geophysical Research Abstracts, 21, EGU2019-5567. Available at: https://meetingorganizer.copernicus.org/EGU2019/EGU20195567.pdf [Accessed: 10 December 2019].

12. Large, W.G. and Yeager, S.G., 2009. The Global Climatology of an Interannually Varying Air-Sea Flux Data Set. Climate Dynamics, [e-journal] 33(2-3), pp. 341-364. doi:10.1007/s00382-008-0441-3

13. Proshutinsky, A., Steele, M. and Timmermans, M.-L., 2016. Forum for Arctic Modeling and Observational Synthesis (FAMOS): Past, Current, and Future Activities. Journal of Geophysical Research: Oceans, [e-journal] 121(6), pp. 3803-3819. doi:10.1002/2016JC011898

14. Uotila, P., Holland, D.M., Morales Maqueda, M.A., Häkkinen, S., Holloway, G., Karcher, M., Kauker, F., Steele, M., Yakovlev, N., Zhang, J. and Proshutinsky A., 2006. An EnergyDiagnostics Intercomparison of Coupled Ice-Ocean Arctic Models. Ocean Modelling, [ejournal] 11(1-2), pp. 1-27. doi:10.1016/j.ocemod.2004.11.003

15. Ilıcak, M., Drange, H., Wang, Q., Gerdes, R., Aksenov, Y., Bailey, D., Bentsen, M., Biastoch, A., Bozec, A. [et al.], 2016. An Assessment of the Arctic Ocean in a Suite of Interannual CORE-II Simulations. Part III: Hydrography and fluxes. Ocean Modelling, [e-journal] 100, pp. 141-161. doi:10.1016/j.ocemod.2016.02.004

16. Platov, G.A., 2011. Numerical Modeling of the Arctic Ocean Deepwater Formation: Part II. Results of Regional and Global Experiments. Izvestiya, Atmospheric and Oceanic Physics, [ejournal] 47(3), pp. 377-392. doi:10.1134/S0001433811020083

17. Zalesny, V.B. and Tamsalu, R., 2009. High-Resolution Modeling of a Marine Ecosystem Using the FRESCO Hydroecological Model. Izvestiya, Atmospheric and Oceanic Physics, [ejournal] 45(1), pp. 102-115. doi:10.1134/S0001433809010071

18. Golubeva, E.N., 2008. Numerical Modeling of the Atlantic Water Circulation in the Arctic Ocean using QUICKEST Scheme. Computational Technologies, 13(5), pp. 11-24 (in Russian).

19. Golubeva, E.N. and Platov, G.A., 2009. Numerical Modeling of the Arctic Ocean Ice System Response to Variations in the Atmospheric Circulation from 1948 to 2007. Izvestiya, Atmospheric and Oceanic Physics, [e-journal] 45(1), pp. 137-151. doi:10.1134/S0001433809010095

20. Marchuk, G.I., Zalesny, V.B. and Kuzin, V.I., 1975. On the Finite Difference and Finite Element Methods in the Global Wind-Driven Ocean Circulation. Izvestiya, Atmospheric and Oceanic Physics, 11(12), pp. 1294-1300 (in Russian).

21. Marchuk, G.I. and Kuzin, V.I., 1983. On the Combination of Finite Element and Splitting-up Methods in the Solution of Parabolic Equations. Journal of Computational Physics, [ejournal] 52(2), pp. 237-272. doi:10.1016/0021-9991(83)90030-X

22. Leonard, B.P., Lock, A.P. and MacVean, M.K., 1996. Conservative Explicit UnrestrictedTime-Step Multidimensional Constancy-Preserving Advection Schemes. Monthly Weather Review, [e-journal] 124(11), pp. 2588-2606. doi:10.1175/15200493(1996)124<2588:CEUTSM>2.0.CO;2 
23. Golubeva, E.N., Ivanov, Ju.A., Kuzin, V.I. and Platov, G.A., 1992. Numerical Modeling of the World Ocean Circulation with the Upper Mixed-Layer Parameterization. Oceanology, 32(3), pp. 395-405 (in Russian).

24. Hunke, E.C. and Dukowicz, J.K., 1997. An Elastic-Viscous-Plastic Model for Sea Ice Dynamics. Journal of Physical Oceanography, [e-journal] 27(9), pp. 1849-1867. doi:10.1175/1520-0485(1997)027<1849:AEVPMF>2.0.CO;2

25. Bitz, C.M. and Lipscomb, W.H., 1999. An Energy-Conserving Thermodynamic Model of Sea Ice. Journal of Geophysical Research: Oceans, [e-journal] 104(C7), pp. 15669-15677. doi:10.1029/1999JC900100

26. Lipscomb, W.H. and Hunke, E.C., 2004. Modeling Sea Ice Transport Using Incremental Remapping. Monthly Weather Review, [e-journal] 132(6), pp. 1341-1354. doi:10.1175/15200493(2004)132<1341:MSITUI>2.0.CO;2

27. Blumberg, A.F. and Mellor, G.L., 1987. A Description of a Three-Dimensional Coastal Ocean Circulation Model. In: N. S. Heaps (ed.), 2013. Three-Dimensional Coastal Ocean Models. Washington, D.C.: American Geophysical Union, pp. 1-16.

28. Platov, G.A. and Middleton, J.F.F, 2001. Notes on Pressure Gradient Correction. Bulletin of the Novosibirsk Computing Center, (7), pp. 43-58. Available at: https://nccbulletin.ru/files/article/platov_3.pdf [Accessed: 10.12.2019].

29. Atadzhanova, O.A., Zimin, A.V., Romanenkov, D.A. and Kozlov, I.E., 2017. Satellite Radar Observations of Small Eddies in the White, Barents and Kara Seas. Physical Oceanography, [e-journal] (2), pp. 75-83. doi:10.22449/1573-160X-2017-2-75-83

30. Kulakov, M.Yu., 2012. About the New Approach to Modelling of Water Circulation of the Arctic Seas. Arctic and Antarctic Research, (2), pp. 55-62. Available at: http://www.aari.ru/misc/publicat/paa/PAA-92/PAA92-06(55-62).pdf [Accessed: 10.12.2019] (in Russian).

31. Harms, I.H. and Karcher, M.J., 1999. Modeling the Seasonal Variability of Hydrography and Circulation in the Kara Sea. Journal of Geophysical Research: Oceans, [e-journal] 104(C6), pp. 13431-13448. doi:10.1029/1999JC900048

32. Doronin, N.Y., 1983. [Simulation of the Barotropic Circulation in the Kara Sea]. In: AARI, 1983. Proceedings of AARI. Saint Petersburg: AARI. Issue 380, pp. 54-62 (in Russian).

33. Doronin, N.Y., 1985. [Generalized Two-Layer Model of the Kara Sea Circulation]. In: AARI, 1985. Proceedings of AARI. Saint Petersburg: AARI. Issue 389, pp. 15-23 (in Russian).

34. Doronin, N.Y., Kuznetcov, V.L. and Proshutinsky, A.Y., 1991. [Circulation of the Water Masses in the Kara Sea]. In: AARI, 1991. Proceedings of AARI. Saint Petersburg: AARI. Issue 424, pp. 34-41 (in Russian).

35. Dmitrenko, I.A., Rudels, B., Kirillov, S.A., Aksenov, Y.O., Lien, V.S., Ivanov, V.V., Schauer, U., Polyakov, I.V., Coward, A., Coward, A. and Barber, D.G., 2015. Atlantic Water Flow into the Arctic Ocean through the St. Anna Trough in the Northern Kara Sea. Journal of Geophysical Research: Oceans, [e-journal] 120(7), pp. 5158-5178. doi:10.1002/2015JC010804

36. Uralov, N.S., 1960. [On the Advective Component of the Heat Balance of the Barents Sea Southern Half]. In: SOI, 1960. SOI Proceedings. Leningrad: SOI. Issue 55, pp. 3-20 (in Russian).

37. Yakovlev, N.G., 1998. Modeling the Atlantic Water Diffusion in the Arctic Ocean. Russian Meteorology and Hydrology, (2), pp. 47-56.

38. Pavlov, V.K. and Pfirman, S.L., 1995. Hydrographic Structure and Variability of the Kara Sea: Implification for Pollutant Distribution. Deep Sea Research Part II: Topical Studies in Oceanography, [e-journal] 42(6), pp. 1369-1390. doi:10.1016/0967-0645(95)00046-1

39. Panteleev, G., Proshutinsky, A., Kulakov, M., Nechaev, D.A. and Maslowski, W., 2007. Investigation of the Summer Kara Sea Circulation Employing a Variational Data Assimilation Technique. Journal of Geophysical Research: Oceans, [e-journal] 112(C4), C04S15. doi:10.1029/2006JC003728 
40. Kaurkin, M.N., Ibrayev, R.A. and Belyaev, K.P., 2016. Data Assimilation in the Ocean Circulation Model of High Spatial Resolution Using the Methods of Parallel Programming. Russian Meteorology and Hydrology, [e-journal] 41(7), pp. 479-486. doi:10.3103/S1068373916070050

41. Stepanov, D.V., 2018. Mesoscale Eddies and Baroclinic Instability over the Eastern Sakhalin Shelf of the Sea of Okhotsk: a Model-Based Analysis. Ocean Dynamics, [e-journal] 68(10), pp. 1353-1370. doi:10.1007/s10236-018-1192-2

42. Ivanov, V.V., Shapiro, G.I., Huthnance, J.M., Aleynik, D.L. and Golovin, P.N., 2004. Cascades of Dense Water around the World Ocean. Progress in Oceanography, [e-journal] 60(1), pp. 47-98. doi:10.1016/j.pocean.2003.12.002

43. Ivanov, V.V., 2011. Intensification of Water Exchange between the Shelf and the Arctic Basin in Conditions of Ice Depletion. Doklady Earth Sciences, [e-journal] 441(1), pp. 15331536. doi:10.1134/S1028334X11110043

44. Nof, D., 1983. The Translation of Isolated Cold Eddies on a Sloping Bottom. Deep Sea Research Part A. Oceanographic Research Papers, [e-journal] 30(2), pp. 171-182. doi:10.1016/0198-0149(83)90067-5

45. Atadzhanova, O.A., Zimin, A.V., Svergun, E.I. and Konik, A.A. 2018. Submesoscale Eddy Structures and Frontal Dynamics in the Barents Sea. Physical Oceanography [e-journal], 25(3), pp. 220-228. doi: 10.22449/1573-160X-2018-3-220-228

About the authors:

Gennady A. Platov - Chief Research Associate, Institute of Computational Mathematics and Mathematical Geophysics, Siberian Branch of Russian Academy of Sciences (6 Academician Lavrentiev prospect, Novosibirsk, 630090, Russian Federation); Associate Professor, Novosibirsk National Research State University (1 Pirogova St., Novosibirsk, 630090, Russian Federation), Dr.Sci. (Phys.-Math.), ResearcherID: A-6598-2014, platov.g@gmail.com

Elena N. Golubeva - Leading Research Associate, Institute of Computational Mathematics and Mathematical Geophysics, Siberian Branch of Russian Academy of Sciences (6 Academician Lavrentiev prospect, Novosibirsk, 630090, Russian Federation); Associate Professor, Novosibirsk National Research State University (1 Pirogova St., Novosibirsk, 630090, Russian Federation), Dr.Sci. (Phys.-Math.), ResearcherID: A-6606-2014, e.golubeva.nsk@gmail.com

Contribution of the co-authors:

Gennady A. Platov - initiation of the research, scientific guidance, statement of the research problem, correction of the mathematical model and carrying out of calculations, qualitative and quantitative analysis of the results, formulation of conclusions, preparation of the paper text, revision of the text, construction of tables, graphs, charts, writing of annotation

Elena N. Golubeva - a review of the literature on the research problem, discussion of the work results, processing and description of the research results, preparation of the paper text, revision of the text, editing and addition of the paper text, visualization / presentation of data in the text

All the authors have read and approved the final manuscript.

The authors declare that they have no conflict of interest. 